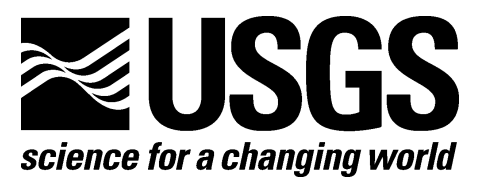

\title{
A Rapid Method for Creating Qualitative Images Indicative of Thick Oil Emulsion on the Ocean's Surface from Imaging Spectrometer Data
}

By Raymond F. Kokaly, Todd M. Hoefen, K. Eric Livo, Gregg A. Swayze, Ira Leifer, lan B. McCubbin, Michael L. Eastwood, Robert O. Green, Sarah R. Lundeen, Charles M. Sarture, Denis Steele, Thomas Ryan, Eliza S. Bradley, Dar A. Roberts, and the AVIRIS Team

Open-File Report 2010-1107 


\section{U.S. Department of the Interior \\ KEN SALAZAR, Secretary}

\section{U.S. Geological Survey \\ Marcia K. McNutt, Director}

U.S. Geological Survey, Reston, Virginia 2010

For product and ordering information:

World Wide Web: http://www.usgs.gov/pubprod

Telephone: 1-888-ASK-USGS

For more information on the USGS-the Federal source for science about the Earth,

its natural and living resources, natural hazards, and the environment:

World Wide Web: http://www.usgs.gov

Telephone: 1-888-ASK-USGS

Suggested citation:

Kokaly, R.F., and others, 2010, A rapid method for creating qualitative images indicative of thick oil emulsion on the ocean's surface from imaging spectrometer data: U.S. Geological Survey Open-File Report 2010-1107, 16 p.

Any use of trade, product, or firm names is for descriptive purposes only and does not imply endorsement by the U.S. Government.

Although this report is in the public domain, permission must be secured from the individual copyright owners to reproduce any copyrighted material contained within this report. 


\section{Contents}

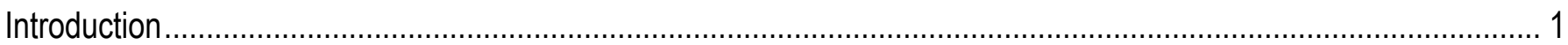

Reflectance spectra of oil:water emulsions and normalized difference ratios. ...................................................... 1

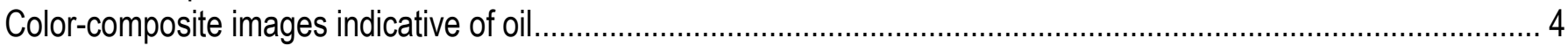

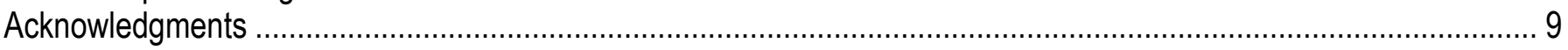

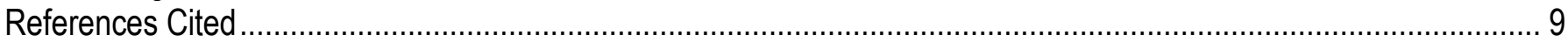

\section{Figures}

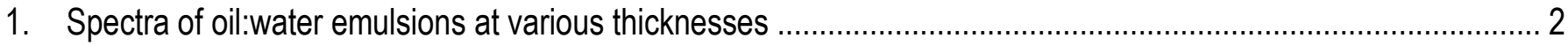

2. AVIRIS spectra of water, oil:water emulsions, and clouds. Wavelengths of interest for normalized

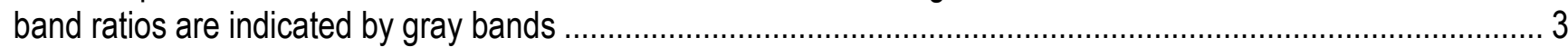

3. Color composite of normalized difference ratios for AVIRIS reflectance data collected May 17, 2010, in the Gulf of Mexico.

4. Color composite of normalized difference ratios for AVIRIS at-sensor radiance data collected May 17, 2010, in the Gulf of Mexico.

5. Color-composite of normalized difference ratios for AVIRIS at-sensor radiance data collected May 19, 2010, in the Gulf of Mexico. 8

\section{Table}

1. AVIRIS channels used in normalized difference ratios. 


\section{A Rapid Method for Creating Qualitative Images Indicative of Thick Oil Emulsion on the Ocean's Surface from Imaging Spectrometer Data}

By Raymond F. Kokaly, ${ }^{1}$ Todd M. Hoefen, ${ }^{1}$ K. Eric Livo, ${ }^{1}$ Gregg A. Swayze, ${ }^{1}$ Ira Leifer, ${ }^{2}$ lan B. McCubbin, ${ }^{3}$ Michael L. Eastwood, ${ }^{4}$ Robert O. Green, ${ }^{4}$ Sarah R. Lundeen, ${ }^{4}$ Charles M. Sarture, ${ }^{4}$ Denis Steele,${ }^{5}$ Thomas Ryan, ${ }^{5}$ Eliza S. Bradley, ${ }^{6}$ Dar A. Roberts, ${ }^{6}$ and the AVIRIS Team

\section{Introduction}

This report describes a method to create color-composite images indicative of thick oil:water emulsions on the surface of clear, deep ocean water by using normalized difference ratios derived from remotely sensed data collected by an imaging spectrometer. The spectral bands used in the normalized difference ratios are located in wavelength regions where the spectra of thick oil:water emulsions on the ocean's surface have a distinct shape compared to clear water and clouds. In contrast to quantitative analyses, which require rigorous conversion to reflectance, the method described is easily computed and can be applied rapidly to radiance data or data that have been atmospherically corrected or ground-calibrated to reflectance. Examples are shown of the method applied to Airborne Visible/Infrared Imaging Spectrometer (AVIRIS; Green and others, 1998) data collected May 17 and May 19, 2010, over the oil spill from the Deepwater Horizon offshore oil drilling platform in the Gulf of Mexico.

\section{Reflectance Spectra of Oil:Water Emulsions and Normalized Difference Ratios}

Measured spectra of oil collected from the Deepwater Horizon spill in the Gulf of Mexico (Clark and others, 2010) show strong spectral features, arising from $\mathrm{C}-\mathrm{H}$ bonds in the oil (fig. 1). Clark and others (2010) have shown that the reflectance spectra of oil change in overall reflectance level and strength of absorption features due to changes in both the oil:water ratio and the thickness of the oil:water emulsion layer.

\footnotetext{
${ }^{1}$ USGS, MS 964 Box 25046, Denver Federal Center, Denver CO 80225, USA. raymond@usgs.gov

${ }^{2}$ Marine Science Institute, University of California, Santa Barbara, CA 93106

${ }^{3}$ Desert Research Institute, 2215 Raggio Parkway, Reno, NV 89512

${ }^{4}$ California Institute of Technology, Jet Propulsion Laboratory, 4800 Oak Grove Drive, Pasadena CA 91109-8099

${ }^{5}$ National Aeronautics and Space Administration, Dryden Flight Research Center, P.O. Box 273, Edwards, CA 93523-0273

${ }^{6}$ Geography Department, University of California, Santa Barbara, CA 93106
} 


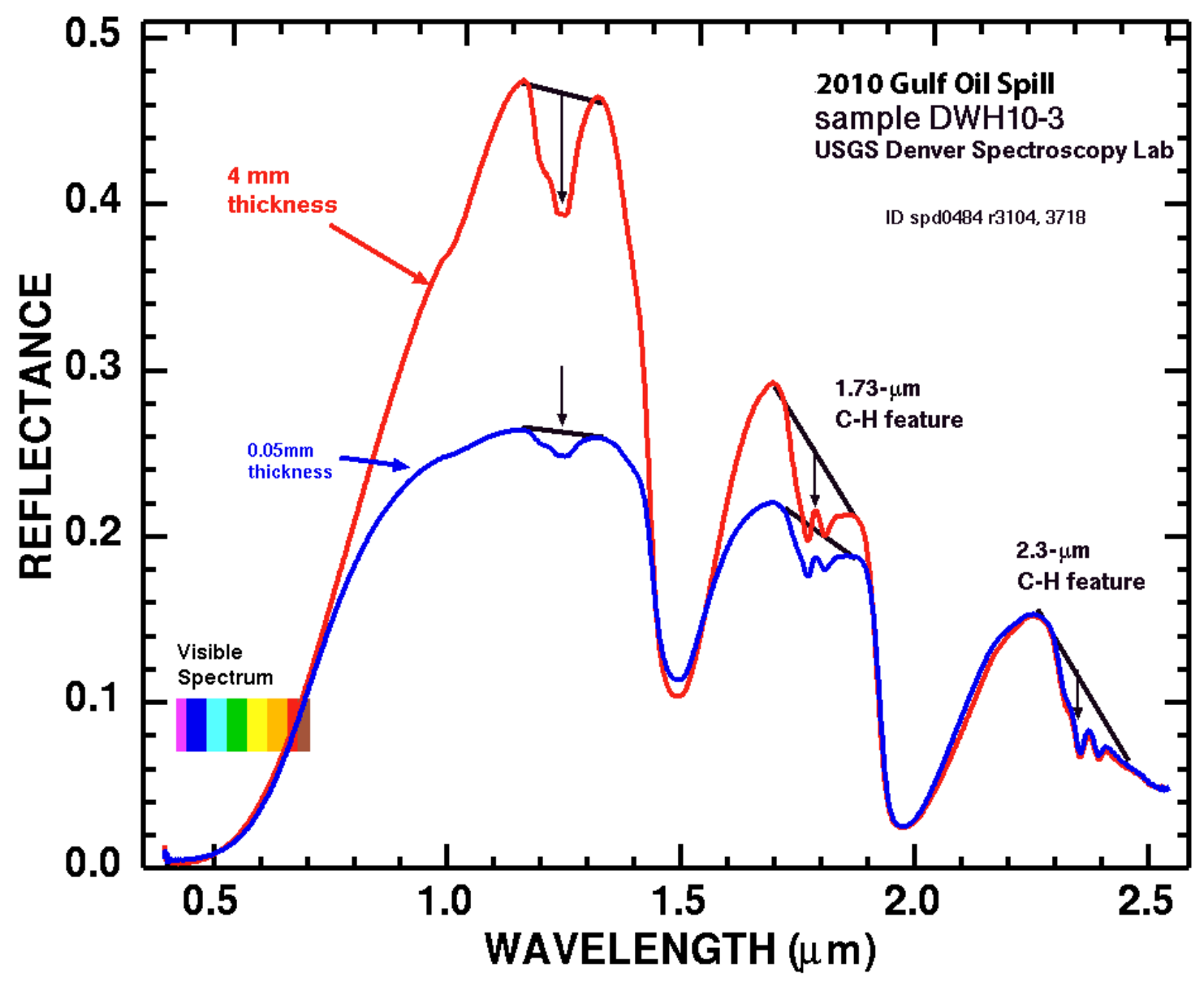

Figure 1. Spectra of oil:water emulsions at various thicknesses (from Clark and others, 2010). Sample collected May 7, 2010. This sample contains approximately 40 percent water as determined by heat separation. Controlled sample depths were created in a cell on a glass window placed over a black substrate and a water substrate. The reflectance was measured over each of these substrates (no difference was observed).

As measured in the laboratory (Clark and others, 2010), the spectra of oil:water emulsions differ greatly from the spectra of water. Spectra extracted from an atmospherically corrected and ground-calibrated AVIRIS image over the Gulf of Mexico collected May 17, 2010, show that these differences are preserved in the remotely sensed data (fig. 2). Note that the significant rise in reflectance from 0.35 to $1.1 \mu \mathrm{m}$ in laboratory (fig. 1) and remotely sensed (fig. 2) spectra of oil emulsions contrasts with the overall decrease in reflectance across this wavelength interval for the spectrum of clear, deep ocean water (see fig. 2). Also note that the $\mathrm{C}-\mathrm{H}$ features, observed at $1.2,1.73$, and $2.3 \mu \mathrm{m}$ in laboratory spectra, are manifest at varying intensities in remotely sensed spectra. 


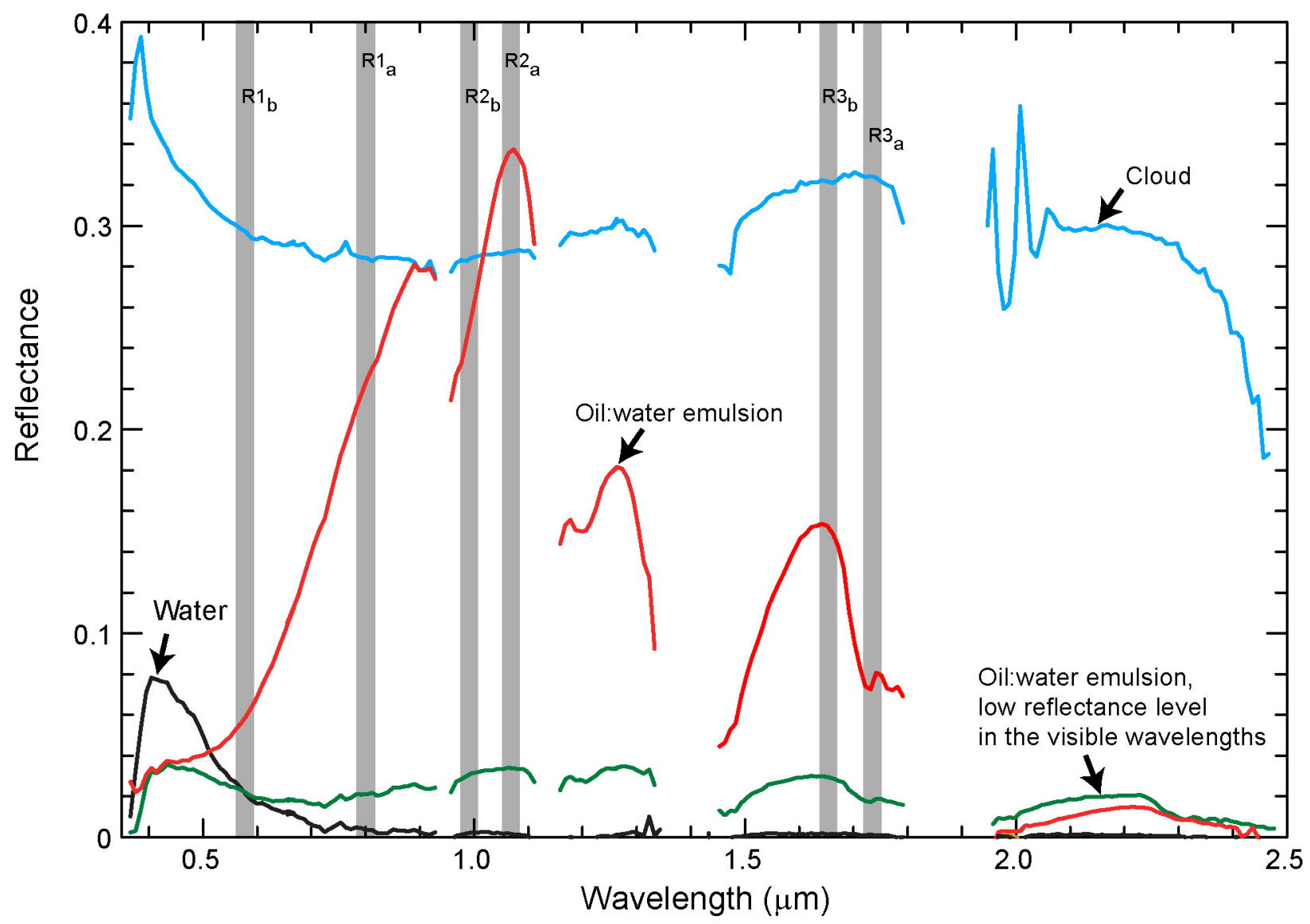

Figure 2 AVIRIS spectra of water, oil:water emulsions, and clouds. Wavelengths of interest for normalized band ratios are indicated by gray bands. AVIRIS channels in wavelength regions of strong atmospheric absorption have been removed.

Based on the spectral features of oil and oil/water emulsions, AVIRIS channels were selected to calculate three normalized difference (ND) ratios:

$$
\begin{aligned}
& \mathrm{ND} 1=\left(\mathrm{R} 1_{\mathrm{a}}-\mathrm{R} 1_{\mathrm{b}}\right) /\left(\mathrm{R} 1_{\mathrm{a}}+\mathrm{R} 1_{\mathrm{b}}\right) \\
& \mathrm{ND} 2=\left(\mathrm{R} 2_{\mathrm{a}}-\mathrm{R} 2_{\mathrm{b}}\right) /\left(\mathrm{R} 2_{\mathrm{a}}+\mathrm{R} 2_{\mathrm{b}}\right) \\
& \mathrm{ND} 3=\left(\mathrm{R} 3_{\mathrm{a}}-\mathrm{R} 3_{\mathrm{b}}\right) /\left(\mathrm{R} 3_{\mathrm{a}}+\mathrm{R} 3_{\mathrm{b}}\right)
\end{aligned}
$$

where $R_{a}$ and $R_{b}$ are values at specific wavelengths in the spectrum, as marked in figure 2 . Normalized difference ratios are commonly used in the analysis of remotely sensed data-for example, the Normalized Difference Vegetation Index (NDVI) (Tucker, 1979). In this case, detection of thick oil:water emulsions on the ocean's surface, the two spectral bands for each ratio were selected at wavelengths where the emulsions have strong reflectance contrast (that is a difference in reflectance level between the two spectral bands due to absorption features), as shown in figure 2. Clouds and clear, deep ocean water have level reflectance spectra across the hydrocarbon absorption features, or in the case of $\mathrm{R} 1_{\mathrm{a}}$ and $\mathrm{R} 1_{\mathrm{b}}$, clear, deep ocean water exhibits the opposite spectral change compared to oil. For each $\mathrm{R}_{\mathrm{a}}$ and $\mathrm{R}_{\mathrm{b}}$ in the normalized difference ratios, values in three AVIRIS channels were averaged (table 1). 
Table 1. AVIRIS channels used in normalized difference ratios.

\begin{tabular}{ccc}
\hline $\begin{array}{c}\text { Normalized } \\
\text { difference } \\
\text { term }\end{array}$ & $\begin{array}{c}\text { AVIRIS 2010 } \\
\text { channels }\end{array}$ & $\begin{array}{c}\text { Wavelengths of channels } \\
\text { (micrometers) }\end{array}$ \\
\hline $\mathrm{R} 1_{\mathrm{a}}$ & $47,48,49$ & $0.793,0.802,0.812$ \\
$\mathrm{R} 1_{\mathrm{b}}$ & $23,24,25$ & $0.580,0.589,0.599$ \\
$\mathrm{R} 2_{\mathrm{a}}$ & $75,76,77$ & $1.063,1.073,1.082$ \\
$\mathrm{R} 2_{\mathrm{b}}$ & $67,68,69$ & $0.986,0.996,1.006$ \\
$\mathrm{R} 3_{\mathrm{a}}$ & $144,145,146$ & $1.722,1.732,1.742$ \\
$\mathrm{R} 3_{\mathrm{b}}$ & $135,136,137$ & $1.632,1.642,1.652$ \\
\hline
\end{tabular}

Reflectance spectra of thick oil:water emulsions have positive values for the first and second normalized differences (ND1 and ND2). However, thick oil:water emulsion spectra are negative for the third normalized difference (ND3). In contrast, clouds exhibit only slight variation in reflectance level for the spectral bands in the normalized differences, resulting in near-zero values for ND1, ND2, and ND3. Reflectance spectra of deep ocean water have relatively higher negative ND1 values and near zero values for ND2 and ND3. For radiance spectra, the trends in ND values are similar, with thick oil:water emulsions having values greater than clouds and clear, deep ocean water for ND1 and ND2 and the lowest values for ND3. An exception to these trends is for very high concentrations of oil in thick oil:water emulsions, in this case the spectra show strong absorption of light in the visible wavelengths, greatly reducing the value of ND1.

\section{Color Composite Images Indicative of Oil}

Color-composite images can be created by assigning ND1, ND2, and ND3 values, computed from the AVIRIS data into red, green, and blue channels, respectively. Figure 3 shows an example color composite computed from AVIRIS ground-calibrated reflectance. The AVIRIS data were converted to reflectance using the method of Clark and others (2002). The area of the image is within the Deepwater Horizon oil spill in the Gulf of Mexico. The AVIRIS data were collected May 17, 2010. The colors in the image were stretched to produce a qualitative indicator of the areas containing thick oil:water emulsions. When thick oil:water emulsions are present in clear, deep ocean water, strong yellow, green, and orange tones in the color-composite image are indicative of areas containing them. These tones result from the relatively higher values of ND1 and ND2 and relatively lower values for ND3 for thick oil:water emulsions as compared to clear, deep ocean water. Blue tones indicate that an oil:water emulsion is not present in sufficient quantity or thickness to cause spectral differences associated with oil:water emulsions in the ND spectral bands (as shown in figs. 1 and 2), or that an oil:water emulsion is absent.

Figure 4 shows the color composite computed for AVIRIS at-sensor radiance data of the same area shown in figure 3. Radiance is a measure of the light that is reflected or emitted from a surface area in a particular direction. In this example of the method applied to AVIRIS data, the radiance data provide a measure of the amount of reflected sunlight measured by the sensor for 
each pixel element within the image. This at-sensor radiance includes a contribution from solar irradiance scattered by the atmosphere back to the sensor. For each channel of AVIRIS, the atsensor radiance is a function of the spectral response function of the channel (Green and others, 1998), the solar irradiance (light from the sun), the scattering and absorption of gases and aerosols in the atmosphere, and the reflectance and scattering properties of the materials in the pixel. The stretched color-composite images from reflectance (fig. 3) and radiance (fig. 4) data are similar in both the colors (yellow and green tones) and patterns indicating thick oil:water emulsion. The similarity demonstrates that this simple method of highlighting areas containing thick oil:water emulsion is applicable to radiance data, as well as reflectance data; however, complications arising from the nonsurface components in the radiance measurement need to be considered when interpreting the image. A disadvantage of computing color-composite images from radiance data is that the spectra of pixels that are indicated as containing thick oil:water emulsions cannot be directly compared to laboratory and field spectra of oil:water emulsions.

With repeated collection of imagery and association of color composites with ocean current data, the movement of thick oil:water emulsion could be tracked. For example, figure 5 shows the color composite derived from AVIRIS data in an area south of the Deepwater Horizon oil platform. The AVIRIS data were collected on May 19, 2010. The AVIRIS color-composite images indicate the possible presence of thick oil:water emulsion (green and yellow tones) within the Gulf of Mexico loop current, as shown by their approximate location in the MODIS (Moderate Resolution Imaging Spectroradiometer) image collected two days earlier on May 17, 2010 .

In clear, deep ocean water, this method can be applied to imaging spectrometer data as a tool for quick assessment of oil spill spatial distribution to facilitate cleanup operations. In nearshore areas, spectral changes caused by bottom reflectance should be considered. If suspended sediment or other nonoil substances are present on the ocean's surface, the spectral properties of that substance should be determined, as its spectral properties might result in ND values similar to thick oil:water emulsions. Imaging spectrometer data should be collected in a manner that reduces sun glint in order to reduce the effect of that component on radiance and reflectance data. 


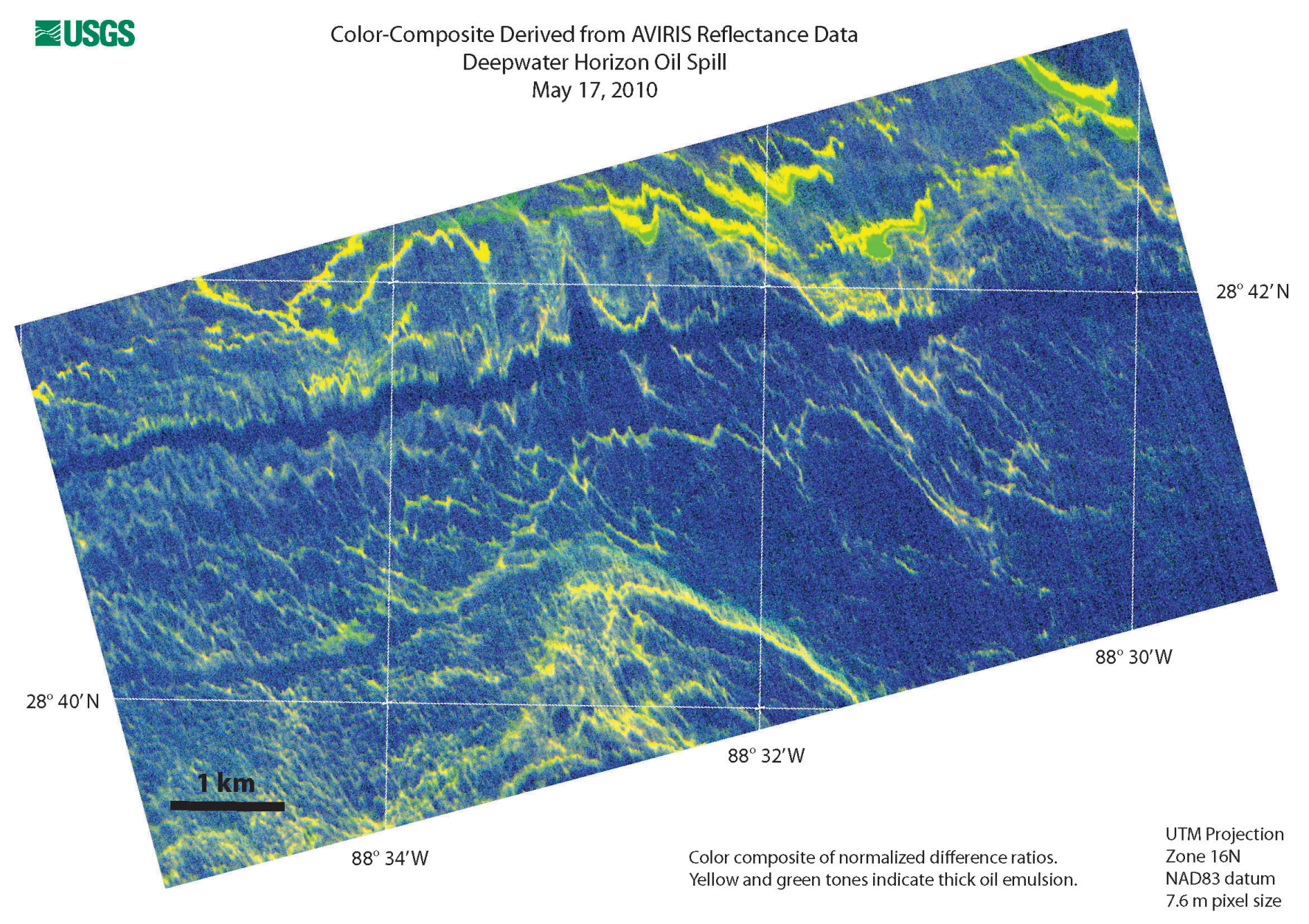

Fgure 3. Color composite of normalized difference ratios for AVIRIS reflectance data collected May 17, 2010, in the Gulf of Mexico. 


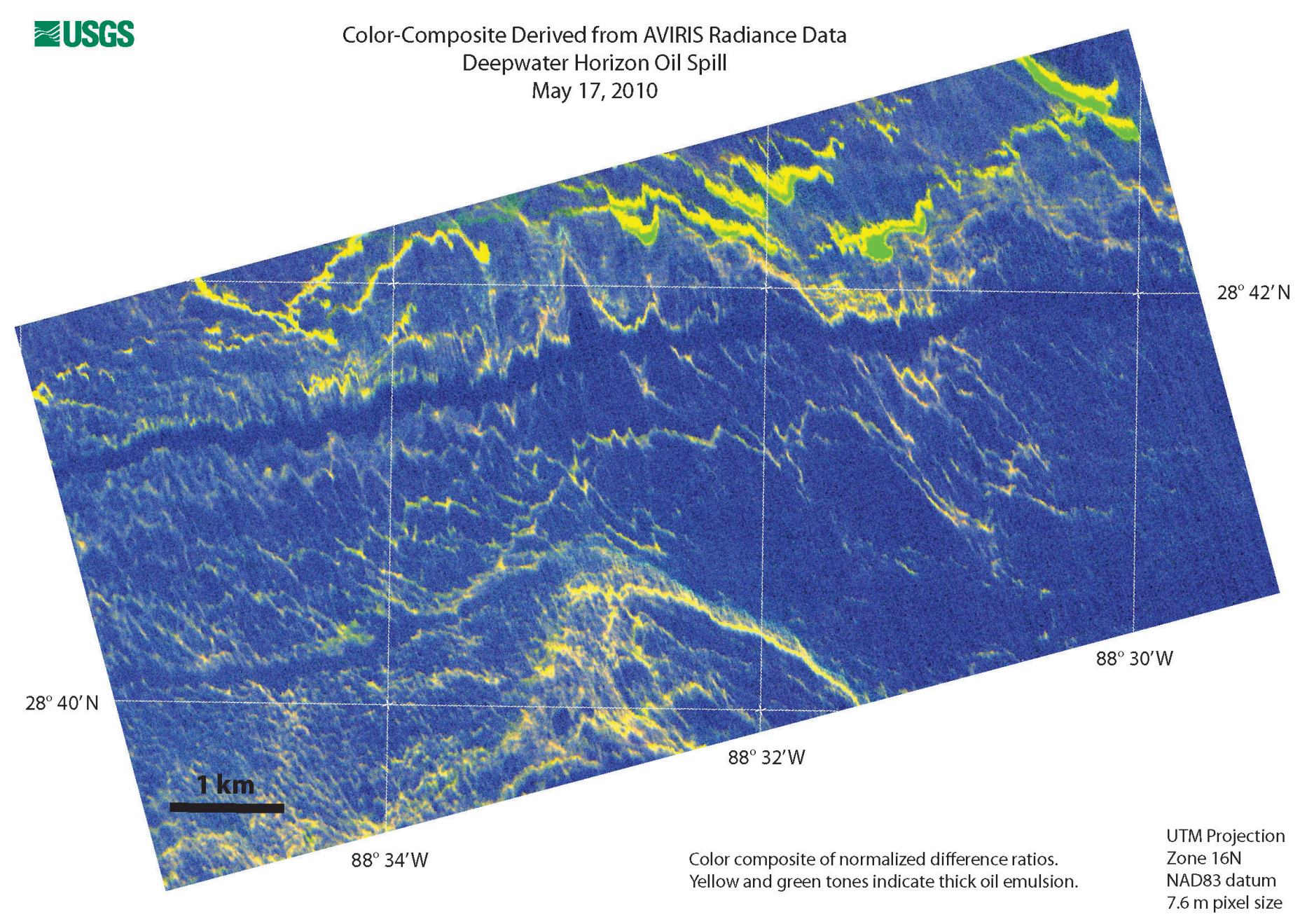

Figure 4. Color composite of normalized difference ratios for AVIRIS at-sensor radiance data collected May 17, 2010, in the Gulf of Mexico. 


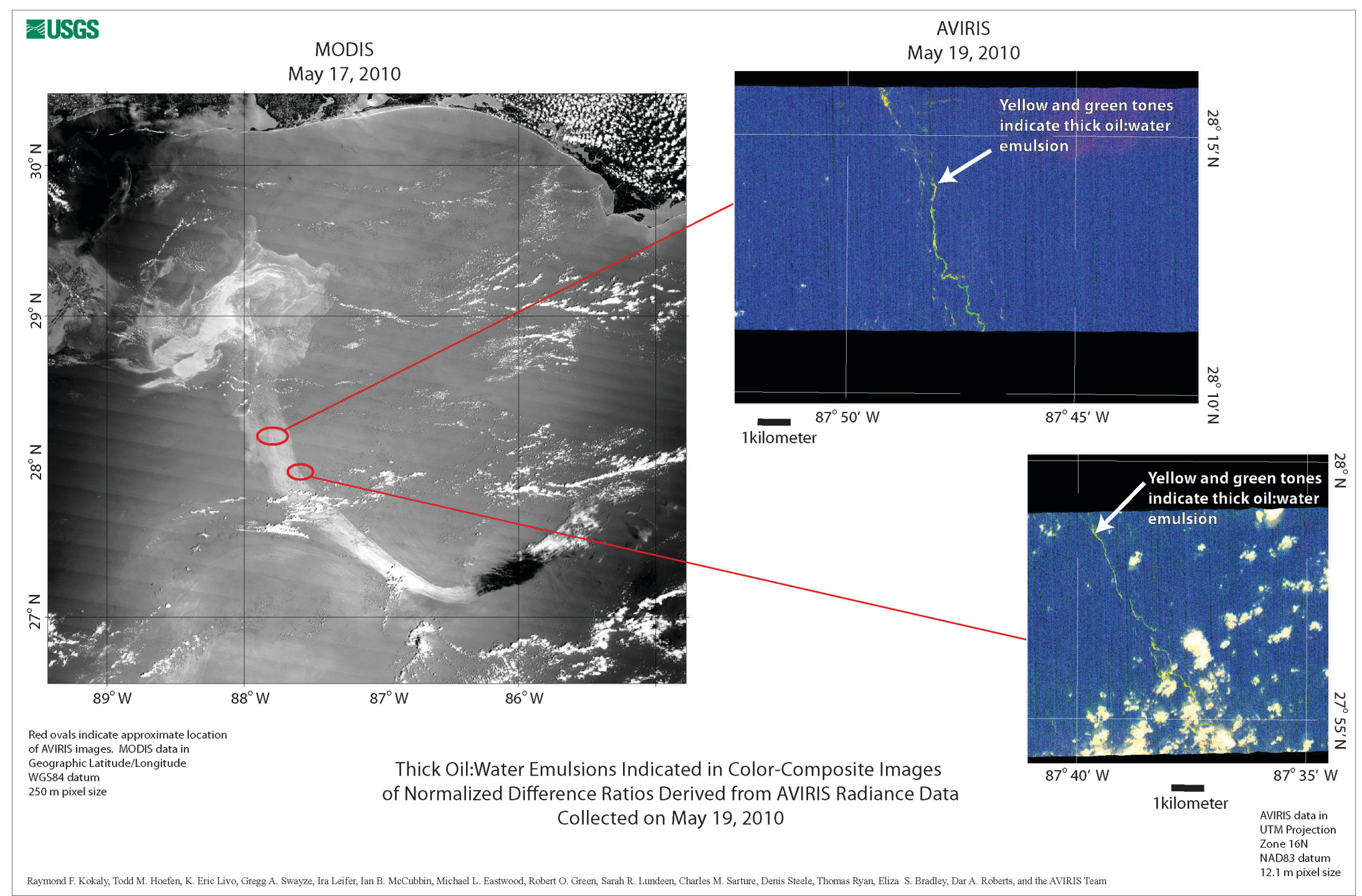

Figure 5. Color composite of normalized difference ratios for AVIRIS at-sensor radiance data collected May 19, 2010, in the Gulf of Mexico. Grayscale image is from MODIS Terra channel one; red boxes on the image mark the locations of the AVIRIS images within the loop current. 


\section{Acknowledgments}

In response to the oil spill in the Gulf of Mexico, the NASA AVIRIS team has shown outstanding dedication to applying science and technology in the public interest. Thanks to NOAA, Ellington Field, NASA Johnson Space Center and Dryden Flight Research Center for their support of the AVIRIS data collection over the Gulf of Mexico. Special thanks to Sonia Gallegos, with the U.S. Naval Research Laboratory, for helping to arrange a sampling trip to the oil spill and for assistance with measurements of field spectra. British Petroleum cooperated in the sampling by providing transportation to the oil spill.

\section{References Cited}

Clark, R.N., Swayze, G.A., Livo, K.E., Kokaly, R.F., King, T.V.V., Dalton, J.B., Vance, S.J., Rockwell, B.W., Hoefen, T., and McDougal, R.R., 2002, Surface reflectance calibration of terrestrial imaging spectroscopy data-A tutorial using AVIRIS., in Green, R.O., ed., Proceedings of the 10th JPL airborne science workshop: JPL publication 02-1.

Clark, R.N., Swayze, G.A., Leifer, I., Livo, K.E., Lundeen, S., Eastwood, M., Green, R.O., Kokaly, R., Hoefen, T., Sarture, C., McCubbin, I., Roberts, D., Steele, D., Ryan, T., Dominguez, R., Pearson, N., and the Airborne Visible/Infrared Imaging Spectrometer (AVIRIS) Team, 2010, A method for qualitative mapping of oil spills using imaging spectroscopy: U.S. Geological Survey Open-File Report 2010-1101.

Green, R.O., Eastwood, M.L., Sarture, C.M., Chrien, T.G., Aronsson, M., Chippendale, B.J., Faust, J.A., Pavri, B.E., Chovit, C.J., Solis, M., Olah, M.R., and Williams, O., 1998, Imaging spectroscopy and the airborne visible/infrared imaging spectrometer (AVIRIS): Remote Sensing of Environment, v. 65, p. 227-248.

Tucker, C.J., 1979, Red and photographic infrared linear combinations for monitoring vegetation: Remote Sensing of Environment v. 8, p. 127-150. 